Volume 2 Nomor 1 Edisi Juni 2013

ISSN 2354-7200
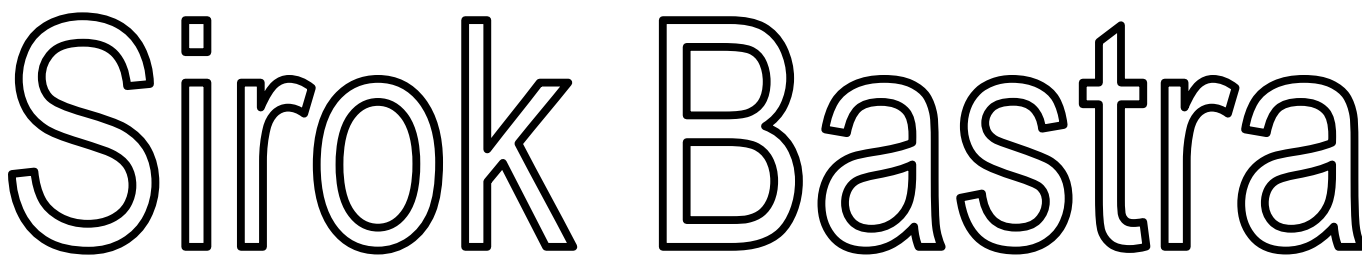

JURNAL ILMIAH KEBAHASAAN DAN KESASTRAAN

\begin{tabular}{|c|c|l|c|c|c|}
\hline $\begin{array}{c}\text { Sirok Bastra } \\
\text { Jurnal Kebahasaan dan } \\
\text { Kesastraan }\end{array}$ & Volume 2 & Nomor 1 & $\begin{array}{c}\text { Hlm. } \\
1-120\end{array}$ & $\begin{array}{c}\text { Pangkalpinang, } \\
\text { Juni 2013 }\end{array}$ & $\begin{array}{c}\text { ISSN } \\
2354-7200\end{array}$ \\
\hline
\end{tabular}

KANTOR BAHASA PROUINSI BANGKA BELITUNG 


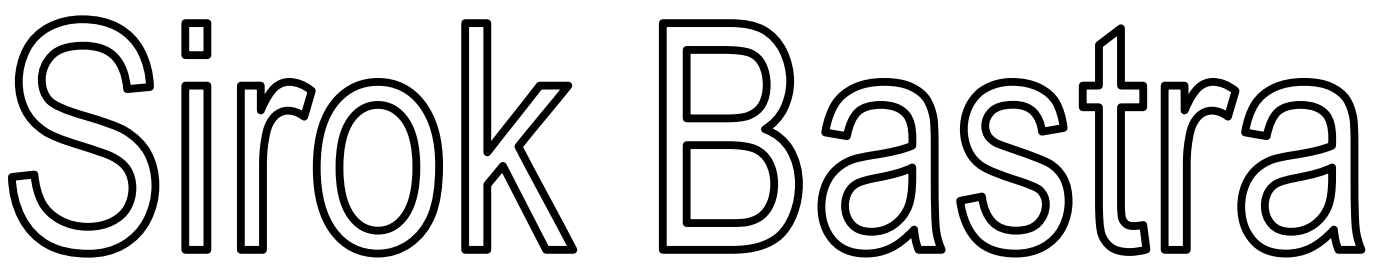

\section{JURNAL ILMIAH KEBAHASAAN DAN KESASTRAAN}

Jurnal ini merupakan wadah informasi mengenai kebahasan, kesastraan, dan pengajarannya yang memuat hasil penelitian, studi kepustakaan, dan tulisan ilmiah bidang kebahasan dan kesastraan serta pengajarannya. Sirok Bastra terbit dua kali setahun, yakni Juni dan Desember, serta terbit sejak Juni 2013.

\section{Penanggung Jawab}

Kepala Kantor Bahasa Provinsi Bangka Belitung Drs. Umar Solikhan, M.Hum.

\section{Mitra Bestari}

Prof. Dr. Agus Nuryatin, M.Hum. (Bidang Sastra dan Pengajarannya)

Prof. Amrin Saragih, Ph.D., M.A. (Bidang Bahasa dan Pengajarannya)

Dr. Felicia Nuradi Utorodewo, M.Hum. (Bidang Bahasa dan Pengajarannya)

Dr. Pujiharto, M.Hum. (Bidang Sastra dan Pengajarannya)

\section{Pemimpin Redaksi}

Rahmat Muhidin, S.S.

\section{Penyunting}

Prima Hariyanto, S.Hum.

\section{Perancang Sampul}

Feri Pristiawan, S.S.

\section{Kesekretariatan}

Khaliffitriansyah, S.Pd.

Dea Letriana Cesaria, S.Hum.

Lia Aprilina, S.Pd.

Andrian Priyatno, A.Md.

Elzam

\section{Alamat Redaksi dan Penerbit}

Kantor Bahasa Provinsi Bangka Belitung

Ruko Permata 7, Jalan Solihin G.P. Km 4, Kota Pangkalpinang, Prov. Kepulauan Bangka Belitung

Telp./Faks.: 0717-438455, Pos-el: sirokbastra@gmail.com

Pemuatan suatu tulisan dalam jurnal ini tidak berarti redaksi menyetujui isi tulisan tersebut. Isi tulisan menjadi tanggung jawab penulis. Tulisan telah ditinjau dan diulas oleh mitra bestari. Setiap karangan dalam jurnal ini dapat diperbanyak setelah mendapat izin tertulis dari penulis, redaksi, dan penerbit. 


\section{PENGANTAR}

Puji syukur ke hadirat Pemilik dan Pencipta semesta ini yang memiliki kuasa atas diri-Nya sendiri. Dialah Tuhan Yang Maha Esa yang telah memberikan rahmat dan hidayah-Nya sehingga Volume 2 Nomor 1 Jurnal Sirok Bastra Tahun 2014 dapat terbit tepat pada waktunya.

Pada edisi ini, dimuat sepuluh tulisan, yakni enam tulisan kesastraan dan empat tulisan kebahasaan. Dalam kajiannya, Anita Rima Dewi melihat kedudukan perempuan Jawa dalam keluarga — tergambar dalam novel Hati Sinden karya Dwi Rahyuningsih — dilihat dari perspektif gender. Berdasarkan penelitian, ditemukan bahwa diskriminasi gender seperti marginalisasi, stereotipe, dan subordinasi melahirkan berbagai kekerasan, yakni ekonomi, fisik, psikis, dan seksual.

Dalam kajiannya, Sarman membahas mitos buluh perindu dalam cerita rakyat Bangka. Mitos Bukit Tambun Tulang memuat struktur geografis yang menunjukkan adanya pola perjalanan hidup tokoh dalam mempertahankan hidup; struktur tekno-ekonomi yang menunjukkan adanya sistem mata pencaharian orang Bangka, antara lain berburu dan berkebun; struktur sosiologis yang menunjukan adanya hubungan sosial antara sesama manusia; dan struktur kosmologis yang menunjukkan adanya keterkaitan antara dunia nyata dan dunia gaib.

Dalam penelitiannya, Iis Afriatiningsih membahas sosok perempuan dalam karya sastra Indonesia yang diwakili oleh Nyai Ontosoroh, Pariyem, Clara yang menghadapi banyak tantangan dalam hidupnya. Hasil analisis menunjukkan bahwa sosok perempuan memiliki sikap, seperti memperjuangkan hidupnya (tergambar dalam tokoh Nyai Ontosoroh), pasrah dengan nasibnya (tergambar dalam tokoh Pariyem), dan nasibnya ada di tangan rakyat kecil (tergambar dalam tokoh Clara). Perjuangan perempuan tersebut berkaitan dengan kritik formalisme, strukturalisme, posstrukturalisme, dan posmoderenisme.

Dalam kajiannya, Asep Supriadi mengaplikasikan teori takmilah yang digagas oleh seorang pakar sastra Melayu bernama Shafie Abu Bakar pada puisi "Idul Fitri" karya Sutardji Calzoum Bachri. Hasil kajian menunjukkan bahwa puisi tersebut menggambarkan nilai-nilai keislaman dengan dimensi sufistik. Puisi itu menggambarkan perenungan eksistensi diri pada Tuhan.

Dalam kajiannya, Ch. Haris Maulana membahas tokoh dan penokohan serta nilai moral dan kekhasan yang ada dalam serial Harry Potter, khususnya seri pertama, Harry Potter dan Batu Bertuah. Nilai moral dan kekhasan yang tersirat dalam serial ini adalah sihir dapat dipelajari dan bukan faktor keturunan, kesetiakawanan, kedisipilinan, kepedulian, dan keingintahuan.

Dalam penelitiannya, Dwi Oktarina menggali aspek hibriditas dan ambivalensi yang terjadi pada tokoh Mata Hari dalam novel Namaku Mata Hari karya Remy Silado. Mata Hari, seorang agen spionase keturunan Belanda-Jawa bekerja pada banyak negara pada saat perang dunia berkecamuk. Selain itu, permainan politik tubuh Mata Hari juga menjadi sebuah hal yang menarik untuk diteliti lebih jauh. Berdasarkan penelitian, didapatkan hasil bahwa ruang-ruang pertemuan antara dua kebudayaan sama sekali tidak bisa dielakkan. Mata Hari sebagai Indo berdarah campuran Belanda-Indonesia tidak dapat melepaskan dirinya dari dua kebudayaan yang melingkupinya, Belanda maupun Indonesia.

Dalam kajiannya, Maria Christa Istiana Kamagi membahas struktur kalimat dan keterbacaan pada buku teks pelajaran bahasa Indonesia. Berdasarkan penelitian, ditemukan kalimat tunggal perluasan subjek, predikat, objek, dan pelengkap, kalimat tunggal perluasan keterangan, kalimat majemuk setara, kalimat majemuk bertingkat, kalimat majemuk bersusun, dan kalimat taklengkap. Selain menjelaskan struktur kalimat yang ada, penelitian ini juga mencoba menganalisis keterbacaan dilihat dari jumlah kata yang digunakan dalam kalimat tersebut. Hasil yang didapat adalah terdapat beberapa kalimat yang masih masuk kategori kalimat sulit dan sangat sulit dipahami.

Dalam kajiannya, Achril Zalmansyah membahas hasil Uji Kemahiran Berbahasa Indonesia (UKBI) guru dan siswa SMP di Kabupaten Lampung Utara. Data yang diperoleh menunjukkan bahwa sebagian besar peserta memperoleh nilai antara 300-400 yang berarti cukup baik. Dengan demikian, dapat dikatakan bahwa UKBI 
merupakan alat uji yang dapat digunakan untuk mengukur penguasaan bahasa Indonesia seorang guru serta penggunaan bahasa Indonesia yang baik dan benar oleh siswa.

Dalam kajiannya, Prima Hariyanto membahas kata berinfiks -er- dalam bahasa Indonesia. Korpus data penelitian ini adalah Kamus Besar Bahasa Indonesia Edisi Ketiga. Berdasarkan penelitian yang dilakukan, ditemukan 62 kata berinfiks -er- yang terdiri dari 14 jenis kelompok makna. Selain memaparkan kata berinfiks yang ada, penelitian ini juga mencoba memaparkan metode pendefinisian lema kata berinfiks yang -er-bermakna 'sama dengan bentuk dasarnya' dalam Kamus Besar Bahasa Indonesia.

Dalam penelitiannya, Hotnida Novita Sary mengkaji perbedaan bentuk verba yang terdapat dalam bahasa Melayu Tinggi dan bahasa Melayu Rendah yang terdapat dalam Injil Matius terjemahan Klinkert. Peneliti mengunduh data dari laman sabda.org. Kedua versi Injil Matius ini kemudian dibandingkan dan dicatat satu ayat dengan ayat yang sama. Hasil pencatatan inilah yang dianalisis. Hasil yang didapatkan dari penelitian ini adalah ragam bahasa Melayu Tinggi cenderung menggunakan bentuk berimbuhan, sedangkan bahasa Melayu Rendah cenderung menggunakan bentuk dasar.

Kami mengucapkan terima kasih kepada para penulis yang telah bersedia menerbitkan karya mereka pada edisi ini. Para penulis merupakan peneliti, pakar, dosen, siswa, dan mahasiswa dari berbagai sekolah, perguruan tinggi, dan instansi. Terima kasih juga kami sampaikan kepada para mitra bestari kami yang telah memberi ulasan terhadap tulisan-tulisan yang masuk ke redaksi.

Demi memenuhi keberagaman isi dan penulis, Sirok Bastra membuka kesempatan bagi para peneliti dan penulis menyampaikan hasil penelitian dan pemikiran mutakhir dalam bidang kebahasaan, kesastraan, dan pengajarannya.

Pangkalpinang, Juni 2014

Tim Redaksi 


\section{UCAPAN TERIMA KASIH UNTUK MITRA BESTARI}

Redaksi Sirok Bastra mengucapkan terima kasih kepada para mitra bestari yang telah meninjau, menimbang, dan mengulas makalah-makalah yang diterbitkan dalam Sirok Bastra Volume 2 Nomor 1, edisi Juni 2014, yakni

Prof. Dr. Agus Nuryatin, M.Hum.

Bidang Sastra dan Pengajarannya

Universitas Negeri Semarang

Semarang, Jawa Tengah

Prof. Amrin Saragih, Ph.D., M.A.

Bidang Bahasa dan Pengajarannya

Universitas Negeri Medan

Medan, Sumatra Utara

Dr. Felicia Nuradi Utorodewo, M.Hum.

Bidang Bahasa dan Pengajarannya

Universitas Indonesia

Depok, Jawa Barat

\section{Dr. Pujiharto, M.Hum.}

Bidang Sastra dan Pengajarannya

Universitas Gadjah Mada

Yogyakarta, Daerah Istimewa Yogyakarta 


\section{DAFTAR ISI}

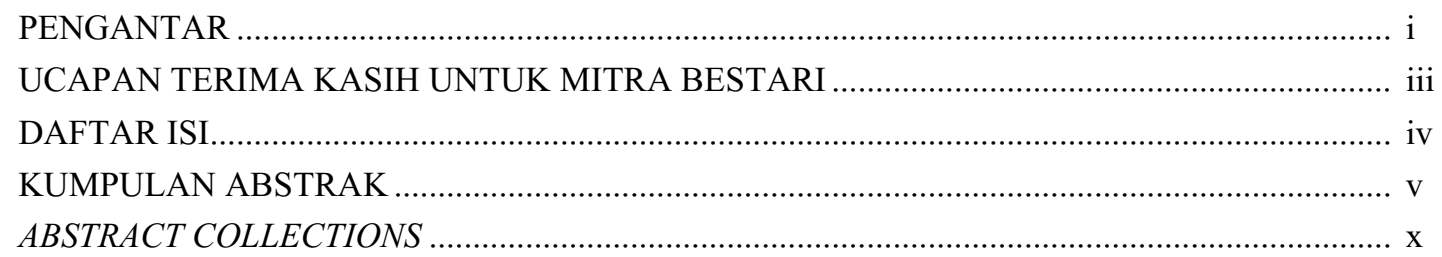

KEDUDUKAN PEREMPUAN JAWA DALAM NOVEL HATI SINDEN KARYA DWI RAHYUNINGSIH DILIHAT DARI PERSPEKTIF GENDER

(The Position of Javanese Women Based on Gender Perspective in Hati Sinden, a Novel by Dwi Rahyuningsih)

Anita Rima Dewi $1-15$

MITOS DALAM CERITA “BUKIT TAMBUN TULANG”

(Myth in "Bukit Tambun Tulang" Story)

Sarman. $17-24$

SOSOK PEREMPUAN DARI ZAMAN KE ZAMAN DALAM KARYA SASTRA INDONESIA: STUDI KASUS TOKOH NYAI ONTOSOROH, PARIYEM, DAN CLARA (Figure of Women from Time to Time in Indonesian Literary Works: A Case Study of Nyai Ontosoroh, Pariyem, and Clara)

Iis Afriatiningsih $25-33$

MEMAHAMI PUISI "IDUL FITRI" DENGAN TEORI TAKMILAH

(Understanding the Poetry "Idul Fitri” by Using Theory of Takmilah)

Asep Supriadi $35-44$

NILAI DAN KEKHASAN SERIAL HARRY POTTER (KAJIAN HARRY POTTER 1: HARRY POTTER DAN BATU BERTUAH)

(Value and Uniqueness of Harry Potter Series [A Study of Harry Potter 1: Harry Potter and The Sorcerers Stone])

Ch. Haris Maulana $45-52$

HIBRIDITAS DAN POLITIK TUBUH DALAM NOVEL NAMAKU MATA HARI KARYA REMY SILADO: SEBUAH TINJAUAN POSKOLONIAL

(Hybridity and Body Politic in Namaku Mata Hari, A Novel Written by Remy Silado: A Postcolonial Study)

Dwi Oktarina $53-61$

STRUKTUR DAN KETERBACAAN KALIMAT PADA BUKU TEKS PELAJARAN BAHASA INDONESIA

(Sentence Structure and Readability in Indonesian Textbook)

Maria Christa Istiana Kamagi. $63-78$ 
UJI KEMAHIRAN BERBAHASA INDONESIA (UKBI) BAGI GURU DAN SISWA SEKOLAH MENENGAH PERTAMA SE-LAMPUNG UTARA

(Indonesian Proficiency Test [UKBI] for Teacher and Junior High School Students All Lampung Utara)

Achril Zalmansyah

KATA BERINFIKS -ER- DALAM BAHASA INDONESIA

(-er- Infixes Words in Indonesian)

Prima Hariyanto

$89-103$

PERBEDAAN BENTUK VERBA PADA BAHASA MELAYU TINGGI DAN BAHASA

MELAYU RENDAH: STUDI KASUS INJIL MATIUS TERJEMAHAN KLINKERT

(Verb Form of Differences in Language Malay Malay Language High and Low: Case Study of The Gospel of Matthew Klinkert Translations)

Hotnida Novita Sary .... $105-120$ 
Dwi Oktarina: Hibriditas dan Politik Tubuh dalam Novel Namaku Mata Hari ...

\title{
HIBRIDITAS DAN POLITIK TUBUH DALAM NOVEL NAMAKU MATA HARI KARYA REMY SILADO: SEBUAH TINJAUAN POSKOLONIAL
}

\section{Hybridity and Body Politic in Namaku Mata Hari, A Novel Written by Remy Silado: A Postcolonial Study}

\author{
Dwi Oktarina \\ Kantor Bahasa Provinsi Bangka Belitung \\ Ruko Permata 7, Jalan Solihin G.P. Km 4, Pangkalpinang \\ Pos-el: oktarinadw@gmail.com
}

(diterima 1 April 2014, disetujui 16 Mei 2014, revisi terakhir 23 Mei 2014)

\begin{abstract}
Abstrak
Penelitian ini menggali aspek hibriditas dan ambivalensi yang terjadi pada tokoh Mata Hari dalam novel Namaku Mata Hari karya Remy Silado. Mata Hari, seorang agen spionase keturunan Belanda-Jawa bekerja pada banyak negara pada saat perang dunia berkecamuk. Selain itu, permainan politik tubuh Mata Hari juga menjadi sebuah hal yang menarik untuk diteliti lebih jauh. Metode yang digunakan dalam penelitian ini adalah metode deskriptif kualitatif. Berdasarkan penelitian yang telah dilakukan, didapatkan hasil bahwa ruang-ruang pertemuan antara dua kebudayaan sama sekali tidak bisa dielakkan. Mata Hari sebagai Indo berdarah campuran Belanda-Indonesia tidak dapat melepaskan dirinya dari dua kebudayaan yang melingkupinya, Belanda maupun Indonesia.
\end{abstract}

Kata kunci: Mata Hari, hibriditas, ambivalensi, politik tubuh

\begin{abstract}
This research discusses the aspects of hybridity and ambivalency of Mata Hari, the main character in the Nama aku Mata Hari, a novel by Remy Silado. Mata Hari, a Dutch-Javanese woman worked as military espionage agent in many countries during world war. In addition, the politic of body also becomes a matter of interest for further investigation. The method used in this research is descriptive qualitative. From the research that has been conducted, showed that the spaces between two cultures can not be avoided. Mata Hari as a Dutch-Javanese mixed blood can not get herself out from the two cultures that surrounded her, Dutch and Indonesia.
\end{abstract}

Keywords: Mata Hari, hybridity, ambivalence, body politic

\section{PENDAHULUAN}

\subsection{Latar Belakang}

Wacana hibriditas dan politik tubuh di Indonesia muncul sebagai akibat dari kolonialisme dan imperialisme yang telah mengakar selama ratusan tahun di negeri ini. Sebagai dua situs penting analisis kajian sastra poskolonial, hibriditas dan politik tubuh sering ditemukan dalam teks-teks sastra Indonesia. Lo dan Gilbert (dalam Dermawan, 2010:33) menyebutkan beberapa problem yang menyangkut budaya kolonial sebagai persoalan dalam studi sastra poskolonial. Problem yang dimaksud adalah masalah bahasa, sejarah, nasionalisme, ruang dan tempat, politik tubuh, dan hibriditas atau pencampuran budaya penjajah-terjajah. Sementara itu, berbagai kemungkinan keagenan yang tercakup dalam studi ini adalah hibriditas, mimikri, dan ambivalensi. Identitas- identitas hibrida yang lahir dari perjumpaan kolonial tidak pernah benar-benar terkendali atau dapat dikendalikan oleh otoritas kolonial (Tickell, 2008:62). Oleh sebab itu, bisa saja ketertindasan yang dialami pihak yang lemah akan menimbulkan perlawanan.

Seperti yang diketahui, fenomena poskolonial melingkupi seluruh dimensi pola hubungan yang terkonstruksi oleh negara yang pernah mengalami masa kolonisasi berikut efek-efek yang ditimbulkannya. Sebagai teks sastra poskolonial, sastra Indonesia sarat dengan muatan seperti itu. Pertumbuhan sastra Indonesia pada awal era 1920-an sampai sekarang kerap bersentuhan dengan dunia poskolonialitas. Karya sastra poskolonial menjadi menarik untuk diamati karena menampilkan pertarungan antara pengarang dengan dunia luar karya sastra yang dikonstruksinya menjadi sebuah karya 
yang utuh. Pengarang sering menampilkan konstruksi ideologis, politis, dan kultural yang dimilikinya serta kemudian direpresentasikan dalam pandanganpandangan tokoh dalam karya yang dibuatnya.

Pandangan-pandangan seperti hibriditas, ambivalensi, dan politik tubuh itulah yang ingin ditampilkan Remy Silado dalam novelnya, yakni Namaku Mata Hari (selanjutnya akan disingkat $N M H)$. Meskipun diterbitkan jauh setelah masa kolonialisme di Indonesia berakhir, karya ini tetap menjadi rekam jejak yang cukup baik dalam merepresentasikan ideologi-ideologi dan gagasan mengenai kolonialisme dan imperialisme. Remy Sylado sebagai pengarang $N M H$ merupakan pengarang yang produktif dalam menghasilkan karyakarya sastra dengan referensi sejarah yang cukup memadai. Beberapa karyanya berlatar sejarah yang kuat, misalnya Kembang Jepun, Parijs van Java, Sam Po Kong, dan 9 Oktober 1740. Selain menulis novel, ia juga menulis kritik, puisi, cerpen, drama, kolom, esai, roman populer, juga buku-buku musikologi, dramaturgi, bahasa, dan teologi (id.wikipedia.org/wiky/remy-sylado).

Novel yang diterbitkan pada 2010 ini menceritakan karakter utama seorang perempuan Indo keturunan Belanda-Indonesia yang bernama Margaretha Geertruida. Pada kemudian hari, ia lebih terkenal dengan nama Mata Hari. Sejarah mencatat bahwa ia terlibat dalam intrik politik, spionase, dan isu-isu sensualitas yang dianggap sangat tabu pada masa-masa itu. Ia menjadi seorang penari erotis, bekerja sebagai agen mata-mata, dan menggunakan kemampuan seksualnya untuk mengorek rahasiarahasia yang berkenaan dengan pejabat-pejabat tinggi militer dua negara yang sedang terlibat perang dunia.

Walaupun memiliki tampilan kebelandabelandaan, sosok Mata Hari malah ingin melebur dan menyatu dengan tradisi orang Jawa di Indonesia. Hal itu disebabkan oleh adanya darah Jawa yang mengalir dalam tubuhnya. Meskipun demikian, ia tetap tidak dapat begitu saja menanggalkan identitas dan kebiasaan hidup Belanda yang telah melekat dalam dirinya sejak kecil. Selain itu, dengan alasan kekecewaan terhadap mantan suaminya, ia memilih untuk melakukan petualangan seksual dengan partner yang berganti-ganti. Tubuh Mata Hari dikonstruksikan menjadi sebuah tubuh yang membawa pandangan-pandangan dan ideologi tertentu.

Bagi pihak penjajah, teks menjadi salah satu alat kontrol kolonial yang paling ampuh. Sebagai sarana komunikasi, teks menjadi kekuatan pendukung dan penyebar paling efektif hegemoni kekuasaan (Aschroft, 2003:x). Wacana pascakolonialisme tidak hanya berkisar pada teks-teks sastra yang terbit pada masa kolonial, tetapi lebih kepada teks-teks sastra yang mewacanakan atau menampilkan jejak-jejak kolonialisme.

Penelitian ini menggunakan kerangka poskolonial untuk menganalisis konstruksi identitas yang dimiliki oleh Mata Hari. Secara umum, dalam karya sastra berbau poskolonial, tema mengenai identitas merupakan sebuah hal yang tidak dapat dibantah. Sejalan dengan konsep hibriditas, permasalahan mengenai identitas menjadi fokus utama penelitian yang kemudian membuat peneliti mengajukan pertanyaan seperti, "Siapa Mata Hari?" atau "Sebenarnya Mata Hari memihak kepada siapa?". Lebih jauh lagi, politik tubuh juga merupakan tema penting dalam novel ini. Tubuh perempuan-dalam hal ini diwakili oleh Mata Hari-telah bertransformasi menjadi sebuah gambaran dari sumber gairah dan hasrat yang berfungsi sebagai penanda dan simbol sebuah identitas.

\subsection{Rumusan Masalah}

Dipilihnya $N M H$ untuk dianalisis karena novel ini menggambarkan bagaimana hibriditas dan politik tubuh yang dialami oleh tokoh Mata Hari. Fokus utama dalam penelitian ini tertuju kepada Mata Hari, sebagai tokoh utama dalam $N M H$. Oleh sebab itu, beberapa pertanyaan yang dapat dirumuskan untuk penelitian ini adalah sebagai berikut.

1. Bagaimana penjelasan mengenai aspek hibriditas dan ambivalensi yang dialami tokoh Mata Hari dalam novel $N M H$ ?

2. Bagaimana permainan politik tubuh Mata Hari diejawantahkan dalam novel $N M H$ ?

\subsection{Tujuan}

Tujuan penelitian ini dapat dijabarkan sebagai berikut. 
1. Mengetahui aspek hibriditas dan ambivalensi yang dialami tokoh Mata Hari dalam novel $N M H$.

2. Mendeskripsikan permainan politik tubuh Mata Hari yang diejawantahkan dalam novel $N M H$.

\subsection{Manfaat}

Manfaat penelitian ini adalah sebagai berikut.

1. Mengungkapkan peran penting perempuan yang tidak hanya terbatas dalam urusan domestik, tetapi juga dapat terlibat dalam intrik politik dan kekuasaan.

2. Menjadi referensi bagi peneliti yang secara khusus bergelut dalam bidang hibriditas, ambivalensi, dan politik tubuh dalam wacana poskolonial.

\subsection{Metode Penelitian}

Dalam melakukan penelitian ini, penulis menggunakan metode studi pustaka dengan model pendekatan kualitatif. Dengan merujuk pada sumbersumber kepustakaan yang ada, penulis berupaya untuk menggambarkan secara menyeluruh aspek hibriditas dan politik tubuh yang dialami tokoh Mata Hari. Dengan menggunakan metode ini, peneliti akan menyajikan data deskriptif berupa kata-kata tertulis. Selain itu, penelitian ini juga merupakan penelitian kualitatif karena tidak menghadirkan unsur perhitungan di dalamnya.

\section{KAJIAN TEORI}

Salah satu situs kunci yang dapat digunakan dalam analisis kajian sastra poskolonial adalah hibriditas dan politik tubuh. Hibriditas adalah istilah yang dipakai untuk mengacu pada interaksi antara bentuk-bentuk budaya yang berbeda yang dapat menghasilkan pembentukan budaya dan identitas baru dengan sejarah dan perwujudan tekstual sendiri (Day, 2008:12). Pengkajian poskolonial selalu difokuskan pada bagaimana sastra meneliti masalah identitas, dengan mengembangkan gagasan tentang hibriditas sebagai salah satu cara untuk mengacu pada interaksi dari beraneka bentuk kultural yang berlainan yang seiring dengan perjalanan waktu mendorong pembentukan kebudayaan-kebudayaan dan identitasidentitas baru yang memiliki sejarah-sejarah serta perwujudan tekstual mereka sendiri (Day, 2008:13).

Dalam kajian poskolonial, hibriditas mengacu pada interaksi bentuk budaya yang berbeda yang dapat menghasilkan pertukaran silang budaya. Dalam konteks ini, hibriditas tidak hanya mengarahkan perhatian pada produk-produk pembauran budaya itu sendiri, tetapi, dan yang lebih penting lagi, juga pada bagaimana hakikat dari produk-produk budaya dan perwujudan mereka dalam ruang historis dan sosial di bawah kolonialisme menjadi salah satu bagian dari pemaksaan dan perlawanan terhadap hubunganhubungan kekuasaan kolonial (Day, 2008:14).

Kajian lain yang menarik untuk diteliti adalah dimainkannya dimensi tubuh untuk menjelaskan ideologi-ideologi yang ingin disampaikan oleh pengarang. Teks sastra dalam konteks ini menjadi media untuk mengomunikasikan daya ekspresif imajinatif itu, sekaligus mengeksplorasikan muatanmuatan substansial yang terdapat di dalamnya yang penuh relasi kuasa (Taufiq, 2010:120). Tubuh dalam kerangka teks poskolonial menjadi unsur penting yang akan menyita perhatian pembacanya. Pengarang memiliki kesempatan untuk mengonstruksi tubuh tersebut. Tubuh dalam teks sastra menjadi bukan semata realitas biologis belaka, melainkan juga mengandung muatan-muatan yang mampu menghubungkan antara dunia teks dengan dunia luar. Tubuh dimetaforakan sebagai representasi kebiasaan imperialis dan merupakan bagian dari bidang administrasi, militer, medis, maupun pedagogis.

\section{HASIL DAN PEMBAHASAN}

\subsection{Hibriditas dan Ambivalensi Tokoh Mata Hari}

Dalam novel NMH, diceritakan seorang perempuan Indo keturunan Belanda-Indonesia yang berperan besar sebagai mata-mata bagi dua negara yang sedang terlibat perang dunia. Mata Hari, dengan segala intrik politik dan sensualitasnya telah menjadi tokoh yang berpengaruh dalam sejarah. Sebagai keturunan Indonesia, tidak dapat dimungkiri bahwa ia merindukan berada di Negeri Khatulistiwa itu ketika ia masih tinggal di Belanda. Meskipun saat itu Indonesia berada dalam cengkraman Belanda, ia sama sekali tidak memedulikannya dan ingin secepatnya berada di Indonesia. Hal itu membuatnya menerima pinangan Rudolph John Campbell Macleod, seorang warga negara Skotlandia yang bekerja sebagai opsir untuk ketentaraan Belanda di Indonesia. Setelah menikah, Mata Hari akhirnya diboyong ke Ambarawa dan mulai merasa tertarik dengan adat istiadat 
leluhurnya di Jawa. Ia memutuskan belajar menari dan akhirnya tertantang untuk menari erotik di depan pembesar-pembesar dan aparat pemerintahan kolonial Belanda.

Sebagai sosok Indo yang bermigrasi dari Belanda menuju Indonesia, Mata Hari dengan susah payah beradaptasi. Seorang Indo adalah satu sosok "Orang Lain" yang di sekitarnya dapat dibentuk identitasidentitas Indonesia, dan sekaligus satu sosok ambiguitas-ambiguitas dan kegelisahan-kegelisahan yang terus-menerus menghantui orang Indonesia selagi mereka menentukan posisi mereka dalam kaitan pengertian "tradisi lawan modernitas" atau "pribumi lawan asing" (Hunter, 2008:138). Mata Hari berada dalam posisi ini. Satu hal yang menarik adalah mengenai identitas ganda yang dimilikinya. Orangorang Belanda menjadikan ia sebagai maskot Timur di mata Barat.

"Saya lega, sebab sampai sejauh ini, semua rencana berjalan dengan baik," kata Cremer optimis, wajah berseri. Jadi, itu artinya kamu harus tampil dengan baik juga, mengguncangkan Batavia dengan tarian erotik Jawa-mu itu. Kamu bisa jadi simbol erotik Timur di mata Barat," (Sylado, 2010:183).

Yang menarik mengenai karakteristik kritik poskolonial ini adalah masalah identitas ganda. Seseorang bisa saja memiliki dua identitas baik sebagai penjajah maupun sebagai yang terjajah. Identitas sebagai sesuatu yang ganda, hibrid, atau yang tak stabil dapat dilihat pada kutipan teks di atas. Sosok Mata Hari masih merupakan orang Belanda betulan dengan sedikit darah Indonesia mengalir di tubuhnya. Akan tetapi, Cremer, pejabat tinggi kolonial dari Batavia telah menganggap Mata Hari sebagai murni orang Timur. Cremer bahkan menganggap bahwa Mata Hari tepat sekali untuk menjadi simbol erotik Timur di mata Barat. Identitas yang dimiliki Mata Hari adalah identitas sebagai penjajah sekaligus terjajah. Ia masih melakoni sifat kebelandaannya sekaligus menjadi subjek terjajah atas tubuhnya sendiri seperti yang diinginkan oleh Cremer dengan cara menjadikannya sebagai penari erotik lambang dari Timur yang akan mengguncang dunia Barat.

Berkaitan dengan tarian erotik yang ditampilkan oleh Mata Hari, ia memang mempelajarinya di padepokan Mbah Kung di daerah pinggiran Kali Elo. Daerah tersebut berada dekat dengan Candi Borobudur. Mata Hari bahkan belajar tarian erotik tersebut dengan melihat relief-relief di Candi Borobudur sebagai inspirasinya. Kekayaan budaya Indonesia yang adiluhung rupanya telah sejak lama menarik perhatian Barat karena dianggap menarik, lugu, dan baru. Hubungan antara Barat dan Timur adalah hubungan kekuatan dominasi, dan hubungan beragam derajat hegemoni yang kompleks. Timur ditimurkan tidak hanya karena ia didapati dalam keadaan "bersifat timur", tetapi juga karena ia dapat dijadikan Timur. Kebudayaan asli Indonesia yang didapati berada dalam keadaan "bersifat Timur" makin dikuatkan pelabelannya menjadi "Timur" oleh pihak-pihak terkait.

Seperti yang lazim diketahui, setiap bangsa memiliki batas-batas kebudayaan dengan bangsa yang lain sehingga ada produksi dan reproduksi tentang kebudayaan yang melekat dalam kelompok tersebut secara internal. Namun, dalam dunia modern terdapat kelompok bangsa yang dominan yang dapat menyeruak masuk ke dalam kebudayaan bangsabangsa yang lain. Dalam hal ini, kebudayaan Barat dipaksa menyelinap masuk ke kebudayaan pribumi atau hal sebaliknya pun dapat terjadi. Hal itu seperti ditunjukkan oleh kutipan di bawah ini.

Kami mendapat seorang babu, dan sudah pandai membuat sejumlah masakan Belanda mulai dari yang repot seperti biefstuk sampai yang gampangan seperti hutspot. Dia pun bisa berbahasa Belanda, khas indo-indo, yaitu bahasa Belanda Argot, misalnya kata-kata yang baku di Belanda 'water closet' disingkat 'wc', di Indonesia menjadi 'kak huis' harafiahnya 'rumah tai' dan belakangan diserap bahasa Indonesia menjadi kakus, (Sylado, 2010:54).

Kejadian seperti di atas sangat dimungkinkan terjadi dalam dunia poskolonial. Penduduk pribumi yang menggunakan bahasa penjajah dalam kesehariannya menjadi suatu hal yang sangat menarik. Percampuran bahasa merupakan sebuah hal yang masuk dalam kerangka hibriditas. Akan tetapi, kebijakan kolonial Belanda menerapkan hal yang berbeda. Mereka membangun dinding pemisah dengan tetap mempertahankan pribumi sebagai pribumi dan penjajah sebagai penjajah. Hal ini terjadi pula dalam ranah bahasa. Meskipun kenyataannya 
terdapat beberapa kata serapan dalam bahasa Indonesia yang berasal dari Belanda, tetapi secara riil, tidak ada yang berubah dari bangun kesadaran orang Indonesia sendiri yang terkonstruksi dalam bahasa.

Selain faktor identitas dan bahasa, perilaku seharihari Mata Hari di Indonesia pun tidak bisa dilepaskan dari kehidupan pribumi. Ia seperti ingin membangun pandangan bahwa ia memang orang Indonesia dan rela menanggalkan identitas kebarat-baratannya agar bisa lebih menyatu lagi dengan kehidupan di negeri Jawa.

Barangkali aku harus melupakan kebiasaan-kebiasaan Barat. Aku sekarang di Timur. Dan aku lihat banyak perempuan desa di perkampungan yang sengaja melanjutkan leluri-leluri lama: tidak memakai BH. Tampak benar di sini BH menjadi penjajahan lahiriah terhadap keleluasaan ragawi, (Sylado, 2010:59).

Aku memakai sarung goyor yang biasa membalut tubuhku sejak aku tinggal di Jawa. aku pun menata rambut menurut kebiasaan sehari-hari dan kebanyakan perempuan Indonesia waktu itu, dua kepang yang dijulai di depan dada, (Sylado, 2010:88).

Perasaan cinta mendalam yang dirasakan oleh Mata Hari terhadap Indonesia memang dimungkinkan terjadi karena telah ada perpaduan rasa antara Barat dan Timur dalam dirinya. Dalam mengisi kehidupannya di pulau Jawa, darah Indonesia yang mengalir dalam tubuhnya menyebabkan Mata Hari berperilaku layaknya perempuan Indonesia kebanyakan. Selain itu, identitas keindonesiaan yang ada dalam dirinya juga tidak begitu saja hilang meskipun ia masih sering berhubungan dengan sesama orang Belanda. Hal itu misalnya dapat dilihat dari kutipan di bawah ini.

Perasaan paling menyiksa dalam diriku sebagai wanita berdarah Indonesia adalah kebiasaan Indonesia mandi dua kali sehari yang tidak terpenuhi di penjara Perancis ini, (Sylado, 2010:12).

Semua akan lupa nama-nama itu, termasuk aku pribadi sebab pada waktunya kelak aku lebih dikenal sebagai Mata Hari, nama yang aku bikin sendiri demi karierku, tanpa upacara saji bubur merah putih seperti lazimnya dalam tradisi Ibu, (Sylado, 2010:15).

Bentuk-bentuk identitas keindonesiaan dapat dengan mudah ditemui melekat pada diri Mata Hari seperti cara mandi dan adat istiadat upacara saji bubur merah putih. Beberapa kali Mata Hari memang telah menegaskan bahwa dirinya memiliki darah Indonesia yang mengalir di dalam tubuhnya. Meskipun demikan, sebagai orang yang lahir di Belanda, mendapat didikan Belanda, dan hidup di lingkungan dunia Barat, Mata Hari masih belum sepenuhnya menanggalkan identitas Baratnya. Dalam pikirannya, masih terdapat konstruksi mendudukkan Timur sebagai sebuah objek yang sesuai dengan anggapan Barat.

Yang aku angankan, bagaimana aku bisa menggali keindahan mistis Jawa itu dengan membiarkan diriku menjadi medium roh moyang ibuku dalam bunyi gamelan. Ketika aku mengangan-angankan ini, yang melintas dalam pikiranku adalah menari, bagaimana aku merdeka dari kaidah estetika Barat yang terlalu teknis dalam tariantariannya, lalu membiarkan tubuhku bergerak leluasa di bawah nada gending yang secara alami menyugesti bahasa tubuhku dalam suatu kaidah estetika yang murni, lugu, liar, dan baru, (Sylado, 2010:17).

Apa yang disampaikan Mata Hari dalam kutipan di atas benar-benar mencerminkan pandangan kaum Barat atas Timur. Said mengungkapkan lebih lanjut (2010:1) bahwa orang Eropa menganggap Timur sebagai barang temuan mereka. Timur telah menjadi tempat yang penuh romansa, makhluk-makhluk eksotik, kenangan, panorama yang indah, dan pengalaman-pengalaman yang mengesankan. Timur adalah sumber bagi peradaban dan bahasa Eropa, dan sebagai bagian dari imajinasi Eropa yang terdalam. Timur adalah "yang lain" (the other) bagi Eropa. Terdapat sebuah gagasan besar yang mampu membuat kebudayaan Eropa menjadi perkasa. Hal itu menyebabkan kebudayaan tersebut mampu menghegemoni kebudayaan-kebudayaan lain di luar Eropa baik secara kultural maupun politik.

Terdapat dualisme dalam pola pikir Mata Hari. Di satu sisi, ia mengagungkan orisinilitas Timur yang kaya akan tradisi dan nilai-nilai luhur yang sama sekali belum tergali dengan maksimal, sementara di pihak lain, ia masih membawa paradigma pola pikir Barat yang mendudukkan Timur sebagai sebuah objek asing dan sama sekali baru dan lugu.

\subsection{Permainan Politik Tubuh Mata Hari}

Mata Hari merupakan gambaran sosok perempuan yang sangat ideal. Kecantikannya merupakan perpaduan antara Timur dan Barat. Hal itu 
menyebabkan banyak lelaki menjadi tergila-gila kepadanya. Tubuh Mata Hari pun tidak dapat dielakkan menjadi sebuah konstruksi politis. Politisasi tubuh menjadi sebuah hal yang menarik untuk diamati. Dalam konteks teks sastra, hubungan antartokoh tidak dapat dilepaskan dari hal-hal semacam itu. Selain itu, pengarang pun dapat diletakkan dalam posisi orang yang mengonstruksi tokoh cerita sebagai tubuh-tubuh yang mengalami proses politisasi.

Mengapa aku terlalu mencintai tubuhku, menjadikan tubuhku sebagai berhala fornikasi, bersenggama dengan begitu banyak lelaki, (Sylado, 2010:13).

Dan, setelah itu aku membuktikan, bahwa tidak ada lelaki yang begitu tangguh untuk sanggup bertahan atas godaan wanita, ketika mereka harus menerima arti kehidupan nyata, bahwa tidak akan ada keindahan paripurna atas naluri lelaki selain di dalam vagina, (Sylado, 2010:10).

Tubuh Mata Hari, seorang penari erotik dan pelacur kelas kakap dikonstruksi oleh Remy Silado sebagai tokoh cerita yang simbolik dalam merepresentasikan bentuk resistensi Sylado sendiri terhadap ketimpangan hubungan yang terjadi antara laki-laki dan perempuan pada masa kolonial. Sylado ingin mengemukakan bahwa tidak selamanya perempuan harus tunduk kepada keinginan laki-laki. Budaya patriarki yang masih sangat kental pada masa itu tidak ayal menjadikan perempuan semata sebagai objek yang lemah. Tubuh Mata Hari dikonstruksi sedemikian rupa sehingga menjadi tubuh yang sangat diminati oleh pihak kolonial.

Di situ aku mencatat dalam ingatan, sejumlah pejabat tinggi negara dan para perwira militer yang biasa berdiri di depan rakyat dengan memasang muka-muka kudus tapi di dalam otaknya tersembunyi pikiran-pikiran kudis atas semata-mata sensasi ranjang, (Sylado, 2010:10-11).

Aku biasa bermain seks dengan tuan-tuan pejabat Belanda dari berbagai kedudukan di hotel itu. Dengannya aku hendak bilang, dalam mencari kesenangan, aku menemukan kepuasan. Dengannya aku percaya diriku perempuan karena ada sejumlah lelaki bukan suamiku yang menyempurnakan naluriku, (Sylado, 2010:272).

Para pejabat kolonial yang menjadi partner seksual Mata Hari tentu saja tak bisa menampik segala pesona yang ditampilkan oleh Mata Hari. Politisasi atas tubuh Mata Hari kemudian menjadi sebuah kekuatan politik
Sylado dalam melakukan resistensi secara terselubung melalui teks sastra ini. Resistensi dengan cara seperti ini menampilkan kekuatan perlawanan kolonial dalam menolak imperialitas yang terjadi. Sebagai simbol dunia Timur yang terkenal atas tarian erotiknya, Sylado mengonstruksi tubuh Mata Hari sebagai tubuh yang sangat digandrungi oleh pihak kolonialis dengan maksud untuk merendahkan mereka secara halus. Hal itu juga menandakan bahwa tidak selamanya pihak kolonial menjadi referen untuk selalu dipuja-puja.

Tubuh perempuan merupakan salah satu sumber kekuatan untuk menaklukkan laki-laki. Di dalam tubuh perempuan terkandung daya tarik seksualitas yang bisa mengendalikan tingkah laku manusia, terutama berkenaan dengan libido laki-laki. Mata Hari sangat menyadari hal itu. Dia menggunakan anugerah tubuh yang menarik perhatian para lelaki untuk memuaskan diri dan melancarkan keinginannya yang terpendam.

Aku sengaja membuka blusku, supaya terlihat sedikit lekuk payudaraku, dan aku yakin "pemandangan" ini mempengaruhi sikap polisi militer yang memeriksa kami, (Sylado, 2010:252).

Dalam pertambahan usia sampai sepuluh tahun ini, pada tahun sekarang, 1914, umurku 38 tahun. Sampai usia 38 tahun ini aku tidak ingat berapa lelaki dari kelas perwira tinggi dan pejabat-pejabat teras atas yang sudah bersenggama denganku. Dalam sensasi ranjang itu, mitra skandalku itu bukan hanya terbuka bicara hal-hal menyenangkan dalam cara-cara bersenggama, tapi juga terbuka bicara hal-hal rahasia negara yang menjadi tanggung jawab dirinya masing-masing sebagai perwira dan pejabat negara, (Sylado, 2010:397).

Dalam tradisi, baik secara kultural maupun struktural, tubuh perempuan masih dianggap sebagai "sesuatu yang lain" dipertanyakan terus-menerus keberadaannya. Keruwetan ini berawal dari persepsi bahwa tubuh perempuan adalah bukan persepsi perempuan itu sendiri; tubuh perempuan menjadi milik pihak lain, terutama kaum laki-laki. Tubuh perempuan adalah politik dalam permainan kehidupan, dalam aturan-aturan moral dan agama. Tubuh perempuan tidak diperkenankan membahas soal otonomi dirinya sendiri sebagai individu yang bebas.

Hal lain yang patut diperhatikan dalam hal politisasi tubuh Mata Hari adalah kemungkinan- 
kemungkinan dijadikannya tubuh Mata Hari sebagai objek yang diperjualbelikan untuk mendapatkan keuntungan. Intinya, Mata Hari menjadikan tubuhnya sendiri sebagai alat tukar yang nantinya akan menghasilkan bayaran tertentu. Aturan-aturan gereja yang mengikatnya ketika menikah dengan Rudolph sama sekali tidak diindahkan. Ia bahkan telah berselingkuh dengan banyak laki-laki sebelum resmi bercerai dengan suaminya tersebut. Petualangan seks yang berganti-ganti dan kekecewaan atas perilaku mantan suaminya mengakibatkan Mata Hari memilih jalan untuk menjadi pelacur profesional dan mendapat bayaran yang sangat tinggi ketika melayani kebutuhan seks para pejabat tinggi yang berasal dari banyak negara.

Mereka tidak tahu keadaan hatiku yang sebenarnya, bahwa aku menertawai keluguan mereka - dan alangkah dekatnya arti keluguan dengan kedunguan — betapa dengan mudah aku, perempuan, memperdaya para lelaki berpangkat tersebut dengan menggunakan senjata kegemulaian, (Sylado, 2010:483).

Jika dalam sepuluh tahun ini aku disuruh oleh kesadaran sendiri untuk menghitung jumlah lelaki berkedudukan tinggi yang pernah selingkuh denganku menikmati sensasi keringnya ladang tersebut, paling-paling aku akan menyebut beberapa nama saja. Di antara mereka yang 'pispot' (singkatan dari 'pribadi istimewa semua para orang terhormat'), aku sebut saja nama Menlu Prancis Roland Dumas, Menhan Prancis Adolph Messimy, jendral Jerman Tragout von Jagow, jendral Jerman Moritz Ferdinand von Bissing, Putra Mahkota Jerman, pejabat tinggi Deplu Prancis Henry Robert de Marguerie, Perdana Menteri Prancis Aristide Briand, (Sylado, 2010:388).

Bukan semata persoalan seks dan menjadi pelacur belaka, Mata Hari menajamkan perannya dengan cara terlibat dalam percaturan politik dunia. Ia menjadi mata-mata bagi dua negara yang sedang terlibat perang dunia, Jerman dan Prancis. Tubuh Mata Hari lagi-lagi mengusung kepentingan politis. Ia menggunakan kemahirannya menari erotik untuk memikat para petinggi kedua negara tersebut dan mengorek informasi untuk mendapat bayaran senilai tujuh kali honorariumnya sebagai penari biasa.

Tidak dapat dimungkiri bahwa tubuh Mata Hari dikontrol dan menjadi ajang bagi perebutan kekuasaan bagi pihak laki-laki yang menginginkannya. Dalam hal ini, Mata Hari menjadi subjek sekaligus objek dalam situasi yang berubah-ubah. Sebagai perempuan, ia menjadi salah satu bagian marjinal dalam tatanan kehidupan sosial dan sangat rentan terhadap rekayasa kekuasaan yang mengepungnya. Ia sendiri menjadi berkuasa karena keuntungan-keuntungan yang diraupnya dari menjual tubuhnya sendiri ke orang lain.

Politisasi atas tubuh perempuan baik melalui mitos, stigmatisasi maupun tindakan seksual sebenarnya dapat dipatahkan dengan menyuarakan tubuh perempuan melalui pembuktian sains, pendidikan, dan penciptaan. Hal itu dilakukan oleh Mata Hari dengan cara belajar dan memperkaya wawasannya dengan pengetahuan yang luas. Tidak mengherankan jika Mata Hari dikenal sebagai 'polyglot harlot' yang menguasai tujuh bahasa dengan sangat baik. Selain itu, ia juga memiliki pengetahuan yang sangat luas sehingga terkadang membuat lawan bicaranya menjadi heran karena melihat perpaduan perempuan cantik dan pintar yang tidak hanya tahu cara bersolek saja.

"Sebagai orang Jerman, apakah Anda membaca buku profesor Jerman, Adolf Bastian?” tanyaku, dan aku yakin dia tidak tahu hal ini. "Profesor Bastian menyebut Indianya Belanda dengan sebutan Indonesia.” Von Bayerling rikuh karena ia memang tidak tahu apa yang kubicarakan. Memangnya apa judul buku Profesor Bastian itu?" Aku mengucapkan tanpa ragu, "Indonesia oder die Insel des Malayschen Archipels.” Dia terkesima. Dia kira aku hanya perempuan cantik dan pesolek yang tidak membaca buku serius, (Sylado, 2010:370).

Daripada melamun sedih, lebih baik aku melanjutkan hobiku sejak kecil: membaca di perpustakaan. Dulu aku berpikir, dan sekarang aku harus membenarkannya, bahwa seorang perempuan modern bukan melulu bisa berpakaian bagus dan karenanya penampilannya akan selalu dilirik orang - seperti yang sudah sejak kecil aku dibiasakan oleh almarhum ibuku - tapi yang penting sekali adalah otaknya harus bagus juga, yang diperolehnya dari kemauannya membaca buku di perpustakaan. Dengan membaca, aku percaya perempuan menjadi perempuan manjadi manusia berharkat, bukan hanya cerdik saja, tapi juga cendikia, (Sylado, 2010:231).

Sebagai kelompok yang lemah, perempuan makin mudah untuk ditindas dan dilemahkan posisinya. Mata Hari menyadari benar akan hal tersebut. Kehadiran tokoh lain yang merupakan bekas babunya, Nyai Kidhal, semakin mengukuhkan pandangannya bahwa perempuan selalu direndahkan dan dilemahkan oleh laki-laki. Tidak terlihat mengejutkan bahwa 
tokoh Mata Hari digambarkan sebagai sosok yang mulia, humanis, dan jujur ketimbang karakter laki-laki lain yang ada di dalam novel. Mata Hari menggambarkan kesediaan untuk menerima bahwa Nyai Kidhal bukanlah pihak yang harus disalahkan, melainkan Ruud, suaminya yang kasar dan berperilaku tidak baik. Sylado berhasil menggambarkan bahwa perempuan tidak hanya seonggok 'tubuh' belaka. Perempuan adalah manusia yang memiliki akal untuk memutuskan sesuatu dan hati yang digunakan untuk mencintai orang lain.

"Sekarang Nyonya Mevrouw mau membunuh saya, silakan. Saya memang salah. Ampun Ndoro Mevrouw, saya susah bicara, saya sedang hamil empat bulan. Adik saya marah dan ingin membunuh Ndoro Tuan, sebab Ndoro Tuan menghamili saya, dan Ndoro Tuan tidak mau tanggung jawab. Tiba-tiba aku seperti diingatkan oleh nurani, bahwa yang salah bukan Nyai Kidhal, tapi Ruud. Nyai Kidhal adalah perempuan. Dan sebagai perempuan, aku sama dengan dia. Perempuan selalu menjadi korban kesalahan lelaki. Lelaki itu Ruud. Ruud itu bajingan, (Sylado, 2010:236-237).

Sebagai sesama perempuan, ia menyadari bahwa bukan sesama perempuan yang harus dibenci, melainkan sistem yang menjadikan lelaki seperti memegang kekuasaan penuh atas diri perempuan. Konstruksi seperti ini tentu saja telah berakar sejak lama. Dalam masyarakat, terjadi proses reproduksi nilai subordinasi perempuan dan superioritas laki-laki yang disetujui oleh banyak pihak. Hal itu tak ayal membuat kedudukan perempuan menjadi semakin terpinggirkan.

Sejauh ini, tubuh Mata Hari masih mengusung konstruksi ideologis dan politis yang berorientasi pada kepentingan pribadinya sendiri. Akan tetapi, tidak dapat dikesampingkan bahwa budaya elite politik yang masih sangat patriarki mendukung segala tindakan politik yang berhubungan dengan pembatasan perempuan sehingga membuat perempuan menjadi sasaran kendali oleh masyarakat dan negara. Perempuan menjadi pihak yang paling riskan untuk dijadikan kambing hitam atas segala masalah yang timbul kemudian. Hal ini pun akhirnya dialami oleh Mata Hari.

“Menurutmu siapa yang salah?' 'Itu tugas Anda untuk mencari dan menemukan jawabannya. Tapi menurut saya, pasti ada seseorang, seorang yang oportunis, yang bermain di belakang layar. Orang itu pasti sosok kontra-spionase Perancis, yang mengenal saya sejak saya masuk ke dalam tugas kepentingan Perancis.” Mengejutkan, dia menyebut sebuah nama. "Kamu mau bilang, sosok yang kamu wasangkai itu Ladoux?" (Sylado, 2010:539).

Hidup Mata Hari akhirnya berakhir tragis karena kelemahannya sebagai perempuan dimanfaatkan dengan cukup cerdik oleh lawan-lawan politiknya. Mata Hari harus merelakan dirinya untuk dihukum di depan prajurit tembak Prancis pada pada Oktober 1917.

\section{SIMPULAN}

Beberapa novelis Indonesia, di antaranya memotret penjajahan Indonesia dari beberapa sudut pandang. Dari sana terdapat semacam gagasan terkait dengan strategi kebudayaan yang tepat untuk membangun kembali kebudayaan Indonesia pasca penjajahan. Ada upaya untuk memberikan semacam ide, bahwa Barat memang lebih daripada Timur dalam satu hal. Akan tetapi, hal itu bukan semata keniscayaan yang harus diterima begitu saja bahwa Timur tidak memiliki kelebihan jika dibandingkan dengan Barat.

Dalam Namaku Mata Hari, ruang-ruang pertemuan antara dua kebudayaan sama sekali tidak dapat dielakkan. Mata Hari sebagai Indo berdarah campuran Belanda-Indonesia tidak dapat melepaskan dirinya dari dua kebudayaan yang melingkupinya, Belanda maupun Indonesia. Beberapa gambaran sikapnya masih menunjukkan arogansi kebaratbaratan. Namun di sisi lain, ia tidak keberatan melepaskan diri dari peradaban yang konon dibawanya dari Barat, misalnya dari cara berpakaian atau keinginannya mempelajari bahasa Jawa hingga menguasai bahasa Jawa Krama Hinggil.

Sylado juga menawarkan teks yang meneguhkan kembali bahwa budaya-budaya yang ada Indonesia sebenarnya memang telah lama menjadi perhatian dunia luar. Entah itu karena memang budaya tersebut bernilai seni tinggi maupun karena dinilai aneh, asing, dan lugu. Dalam novel ini, Sylado menghadirkan bentuk rupa wajah kolonial yang bermacam-macam, terutama dalam hal politisasi atas tubuh Mata Hari. Para lelaki penguasa kolonial digambarkan begitu gandrung terhadap kecantikan dan erotisme Timur yang ditampilkan oleh Mata Hari. Dengan begitu, karya ini menrepresentasikan perempuan yang berada 
“di atas" laki-laki. Mata Hari menggunakan tubuhnya sebagai alat pengontrol laki-laki.

Tubuh dalam kajian teks sastra poskolonial menarik karena ia bukan hanya menjadi dimensi biologis semata melainkan juga menjadi dimensi yang sarat akan muatan ideologis, politis, ekonomis, dan kultural. Tubuh menjadi semacam kekuatan yang dapat menjadi penghubung antara teks dalam sastra dengan realitas dunia luar. Tubuh Mata Hari menjadi tubuh yang dikonstruksi untuk membawa pandanganpandangan si pengarang mengenai dunia patriarkal kolonial.

Sylado membawa pembaca menuju sebuah strategi teks yang menghadirkan perspektif, terutama posisi antara yang dipandang dan memandang. Hal itu karena wacana ini memang mempersoalkan wilayah perspektif, pembedaan sudut pandang antara yang dijajah dan yang menjajah, dalam posisi antara yang dipandang dan memandang. Dengan kata lain, jika the other ada dan terekam dalam karya, itu tak lebih untuk mengukuhkan konsepsi dan keberadaan serta dominasi kolonial yang selalu saja Barat. Mungkin dibutuhkan strategi tersendiri untuk menyikapi warisan tradisi dan warisan kolonial dengan menyadari bahwa kita memang berada dalam persilangan budaya dan ruang pertemuan hibriditas tidak dapat begitu saja dielakkan kehadirannya.

Demikianlah, tulisan ini mungkin hanya akan sedikit memberi kontribusi bagi perkembangan dunia poskolonial dan rekam jejaknya di masa sekarang. Saya berharap kajian-kajian atas karya sastra dapat terus digalakkan dengan melihat dari berbagai perspektif, agar kajian tersebut dapat memberikan gambaran yang lebih utuh bagi perkembangan dunia sastra di Inonesia.

\section{DAFTAR PUSTAKA}

Ashcroft, Bill dan Gareth Griffiths dan Helen Tiffin. 2003. Menelanjangi Kuasa Bahasa Teori dan Praktik Sastra Poskolonial, diterjemahkan oleh Fati Soewandi \& Agus Mokamat. Yogyakarta: Qalam.

Day, Tony dan Keith Foulcher. 2008. "Bahasan Poskolonial dalam Sastra Indonesia Modern,” dalam Sastra Indonesia Modern Kritik Poskolonial, Edisi Revisi Clearing a Space edisi revisi, Keith Foulcher dan Tony Day (ed.). Jakarta: Yayasan Obor dan KITLV.

Dermawan, Rusdian Noor. 2010. Poskolonialisme dalam Roman Bumi Manusia Karya Pramoedya Ananta Toer: Perlawanan Pramoedya terhadap Kolonialisme dan Feodalisme. Yogyakarta: Beranda Publishing.

Hunter, Thomas M. 2008. “Indo sebagai ‘Orang Lain’ Identitas, Kegelisahan, dan Ambiguitas dalam Salah Asoehan,” dalam Sastra Indonesia Modern Kritik Poskolonial, Edisi Revisi Clearing a Space edisi revisi Keith Foulcher dan Tony Day (ed.). Jakarta: Yayasan Obor dan KITLV.

Said, Edward W. 2010. Orientalisme: Menggugat Hegemoni Barat dan Mendudukkan Timur sebagai Subjek, diterjemahkan oleh Achmad Fawaid. Yogyakarta: Pustaka Pelajar.

Sylado, Remy. 2010. Namaku Mata Hari. Jakarta: Gramedia Pustaka Utama.

Taufiq, Akhmad. 2010. “Konstruksi Politik Tubuh dalam Teks Sastra Poskolonial.” Makalah Lepas. Prodi Pendidikan Bahasa dan Sastra Indonesia, FKIP Universitas Jember.

Tickell, Paul. 2008. "Cinta di Masa Kolonialisme Ras dan Percintaan dalam Sebuah Novel Indonesia Awal," dalam Sastra Indonesia Modern Kritik Poskolonial, Edisi Revisi Clearing a Space edisi revisi, Keith Foulcher dan Tony Day (ed.). Jakarta: Yayasan Obor dan KITLV.

Tim Wikipedia. 2013. "Remy Silado," dalam http://id.wikipedia.org/wiki/Remy_Silado diakses pada Senin, 2 Juli 2013, pukul 10.14 . 